\title{
Effect of Empagliflozin Versus Placebo on Plasma Volume Status in Patients with Acute Myocardial Infarction and Type 2 Diabetes Mellitus
}

\author{
Yu Hoshika Yoshiaki Kubota (D) - Kosuke Mozawa · Shuhei Tara · Yukichi Tokita Kenji Yodogawa • \\ Yu-ki Iwasaki · Takeshi Yamamoto $\cdot$ Hitoshi Takano $\cdot$ Yayoi Tsukada $\cdot$ Kuniya Asai $\cdot$ Masaaki Miyamoto \\ Yasushi Miyauchi · Eitaro Kodani · Mitsunori Maruyama · Jun Tanabe · Wataru Shimizu
}

Received: May 17, 2021 / Accepted: June 15, 2021 / Published online: July 8, 2021

(c) The Author(s) 2021

\section{ABSTRACT}

Introduction: Plasma volume status (PVS), a parameter of the discrepancy between actual plasma volume (PV) and ideal PV, has been recently evaluated as a prognostic marker in patients with heart failure. This subgroup analysis of the EMBODY trial was designed to determine whether a sodium-glucose cotransporter 2 (SGLT2) inhibitor affects the alleviation

Y. Hoshika · Y. Kubota ( $₫) \cdot$ K. Mozawa · S. Tara

Y. Tokita $\cdot$ K. Yodogawa $\cdot$ Y. Iwasaki .

T. Yamamoto $\cdot$ H. Takano $\cdot$ Y. Tsukada $\cdot$ K. Asai · M. Miyamoto $\cdot$ W. Shimizu

Department of Cardiovascular Medicine, Nippon

Medical School, 1-1-5, Sendagi, Bunkyo-ku, Tokyo 113-0022, Japan

e-mail: ykubota@nms.ac.jp

Y. Miyauchi

Department of Cardiovascular Medicine, Nippon Medical School-Chiba Hokuso Hospital, Chiba, Japan

E. Kodani

Department of Cardiovascular Medicine, Nippon Medical School-Tama Nagayama Hospital, Tokyo, Japan

M. Maruyama

Department of Cardiovascular Medicine, Nippon Medical School-Musashi Kosugi Hospital, Tokyo, Japan

J. Tanabe

Department of Cardiovascular Medicine, Shizuoka

Medical Center, Shizuoka, Japan of heart failure and improvement of PVS in patients after acute myocardial infarction (AMI) with congestive heart failure (CHF).

Methods: The EMBODY trial was a prospective, multicenter, randomized, double-blind, placebo-controlled trial to identify the effect of an SGLT2 inhibitor on cardiac sympathetic hyperactivity in patients with AMI and type 2 diabetes mellitus (T2DM) in Japan. In total, 105 patients were randomized (1:1) to receive $10 \mathrm{mg}$ empagliflozin or a placebo (once daily), 2 weeks after the onset of AMI. In this subanalysis, we investigated the time-course of PVS at baseline and weeks 4, 12, and 24 .

Results: Overall, 96 patients were included in the subgroup analysis set (age $64.3 \pm 10.9$ years, $80.2 \%$ men; 46 in the empagliflozin group and 50 in the placebo group). Body weight and PVS decreased in the empagliflozin group compared with the placebo group at 24 weeks $(-2.2$ vs. $+0.1 \mathrm{~kg}, P<0.001$, and -5.1 vs. $-0.3 \%$, $P<0.001$, respectively). Decreased PVS, defined as a change in PVS of $<-4.5 \%$, was associated with the administration of empagliflozin (odds ratio 2.61, 95\% confidence interval 1.11-6.15, $P=0.028)$. N-terminal pro b-type natriuretic peptide levels decreased in both the empagliflozin and placebo groups (1028.7-370.3 pg/mL, $P<0.001$, and $1270.6-673.7 \mathrm{pg} / \mathrm{mL}, P<0.01$, respectively).

Conclusion: Empagliflozin reduced the body weight and PVS. Early SGLT2 inhibitor administration in patients with AMI, CHF, and T2DM 
can therefore be effective in reducing the body weight and PVS.

Trial Registration: UMIN 000030158.

Keywords: Acute myocardial infarction; Congestive heart failure; Empagliflozin; Plasma volume status; Sodium-glucose cotransporter 2 (SGLT2) inhibitor

\section{Key Summary Points}

Why carry out this study?

Plasma volume status (PVS), an indication of the discrepancy between actual plasma volume (PV) and ideal PV, has been recently evaluated as a prognostic marker in patients with heart failure.

This trial was designed to determine whether a sodium-glucose cotransporter 2 (SGLT2) inhibitor (empagliflozin) affected the improvement of heart failure and PVS in patients after acute myocardial infarction (AMI) with congestive heart failure (CHF).

\section{What was learned from the study?}

Empagliflozin reduced not only the body weight but also PVS.

The results suggest that early SGLT2 inhibitor administration in patients with AMI, CHF, and T2DM can be effective in reducing the body weight and PVS.

\section{INTRODUCTION}

Plasma volume status (PVS) is a differential marker used in the case of a discrepancy between actual plasma volume (PV) and ideal $\mathrm{PV}$; it has recently been evaluated as a prognostic marker of heart failure $[1,2]$. Actual PV has been validated previously [3] and is derived from the values of the hematocrit and the weight of subjects compared with directly measured values of PV, using the curve fitting technique.

$$
\begin{aligned}
\text { Actual PV }= & (1-\text { hematocrit }) \\
& \times[a+(b \times \text { body weight in } \mathrm{kg})]
\end{aligned}
$$

where hematocrit is a fraction, $a=1530$ in males and 864 in females, and $b=41$ in males and 47.9 in females.

Using the body weight, the ideal PV is calculated from the following well-established formula [1]:

$$
\text { Ideal PV }=c \times \text { body weight }(\mathrm{kg})
$$

where $c=39$ in males and 40 in females.

Subsequently, relative PVS, an index of the degree of deviation in ideal PV, can be calculated using the Kaplan-Hakim formula as follows [1]:

$$
\begin{aligned}
\text { PVS }= & {[(\text { actual PV-ideal PV }) / \text { ideal PV }] } \\
& \times 100(\%)
\end{aligned}
$$

The EMBODY trial is a prospective, multicenter, randomized, double-blind, and placebo-controlled trial for identifying the effect of empagliflozin, a sodium-glucose cotransporter 2 (SGLT2) inhibitor, on cardiac sympathetic hyperactivity in patients with acute myocardial infarction (AMI) and type 2 diabetes mellitus (T2DM) in Japan [4, 5].

This post hoc analysis of the EMBODY trial was designed to determine whether the SGLT2 inhibitor improves PVS in patients with diabetes with congestive heart failure (CHF) after AMI.

\section{METHODS}

In the subgroup analysis of the EMBODY trial, a total of 105 patients with T2DM were randomized (1:1) to receive $10 \mathrm{mg}$ empagliflozin once daily or the placebo, both within 2 weeks of the onset of AMI. Here, we investigated the timecourse of changes in PVS at baseline and at weeks 4, 12, and 24. All patients provided informed consent to participate in the trial 
between February 2018 and March 2019. The inclusion and exclusion criteria have already been published [3]. Six patients in the empagliflozin group and three patients in the placebo group withdrew their consent and were thus excluded before the medication was initiated.

\section{Ethics}

The EMBODY trial was registered at the UMIN in November 2017 (ID: 000030158). Ethics approval was obtained from the local institutional review board of each participating center. The trial was conducted in full compliance with the articles of the Declaration of Helsinki and according to the Ethical Guidelines for Medical and Health Research Involving Human Subjects established by the Ministry of Health, Labour, and Welfare and the Ministry of Education, Culture, Sports, Science, and Technology in Japan. After initial screening for eligibility using prior medical records, each patient received an adequate explanation of the trial plan before they provided written informed consent. All participants provided written informed consent prior to study enrolment.

\section{RESULTS}

In total, 96 patients were included in the subgroup analysis set (age $64.3 \pm 10.9$ years, $80.2 \%$ men, with 46 and 50 patients in the empagliflozin and placebo groups, respectively). The baseline characteristics were not significantly different between the treatment groups, including left ventricular ejection fraction, and New York Heart Association functional classification (Table 1). During the trial period, no significant differences were observed in terms of the dose and oral administration rate of the optimal medical treatment (including diuretics) between the two groups (Table 2). All patients received both revascularization and heart failure treatments. The empagliflozin group showed significantly decreased body weight and PVS compared with the placebo group at 24 weeks $(-2.2 \quad$ vs. $+0.1 \mathrm{~kg}, \quad P<0.001, \quad$ and $-5.1 \pm 5.8 \% \quad$ vs. $\quad-0.3 \pm 7.2 \%, \quad P<0.001$, respectively) (Fig. 1a-c; Table 2 ). Therefore, an
Table 1 Baseline patient characteristics

\begin{tabular}{|c|c|c|c|}
\hline $\begin{array}{l}\text { Patient } \\
\text { characteristics }\end{array}$ & $\begin{array}{l}\text { Empagliflozin } \\
\text { group, } n=46\end{array}$ & $\begin{array}{l}\text { Placebo } \\
\text { group, } \\
n=50\end{array}$ & $P$ \\
\hline Age, year (SD) & $63.9(10.4)$ & $64.6(11.6)$ & 0.7 \\
\hline Male, $n(\%)$ & $38(82.6)$ & $39(78.0)$ & 0.6 \\
\hline $\begin{array}{l}\text { Body weight, kg } \\
\text { (SD) }\end{array}$ & $70.1(13.7)$ & $68.1(14.4)$ & 0.4 \\
\hline BMI, $\mathrm{kg} / \mathrm{m}^{2}(\mathrm{SD})$ & $25.2(3.7)$ & $25.2(4.1)$ & 0.9 \\
\hline $\begin{array}{l}\text { Systolic blood } \\
\text { pressure, mmHg } \\
(\mathrm{SD})\end{array}$ & $129.7(11.9)$ & $\begin{array}{l}123.1 \\
(15.7)\end{array}$ & 0.1 \\
\hline Hypertension, $n(\%)$ & $38(82.6)$ & $39(78.0)$ & 0.6 \\
\hline Dyslipidemia, $n(\%)$ & $34(73.9)$ & $36(72.0)$ & 1.0 \\
\hline Smoking, $n(\%)$ & $24(52.2)$ & $27(54.0)$ & 0.9 \\
\hline \multicolumn{4}{|c|}{ Transthoracic echocardiography } \\
\hline $\begin{array}{l}\text { Left ventricular } \\
\text { ejection fraction, } \\
\%(\mathrm{SD})\end{array}$ & $55.1(14.2)$ & $55.0(13.7)$ & 0.97 \\
\hline Average E/e' (SD) & $13.47(7.24)$ & $\begin{array}{l}13.73 \\
(6.26)\end{array}$ & 0.8 \\
\hline $\begin{array}{l}\text { TRPG, mmHg } \\
\text { (SD) }\end{array}$ & $17.59(7.48)$ & $\begin{array}{l}20.71 \\
\quad(11.49)\end{array}$ & 0.2 \\
\hline \multicolumn{4}{|c|}{ Heart failure medication at randomization visit, $n(\%)$} \\
\hline$\beta$-Blocker & $41(89.1)$ & $38(76.0)$ & 0.1 \\
\hline Diuretic & $8(17.4)$ & $11(22.0)$ & 0.6 \\
\hline MRA, & $11(23.9)$ & $12(24.0)$ & 1.0 \\
\hline ACEI & $23(50.0)$ & $28(56.0)$ & 0.6 \\
\hline $\mathrm{ARB}$ & $22(47.8)$ & $19(38.0)$ & 0.4 \\
\hline
\end{tabular}

Glucose-lowering medication at randomization visit, $n$ (\%)

$\begin{array}{llll}\text { Biguanide } & 7(15.2) & 6(12.0) & 0.77 \\ \text { DPP-4 inhibitor } & 20(43.5) & 23(46.0) & 0.84\end{array}$

NYHA classification, \%

$\begin{array}{llll}\text { I/II } & 77.8 / 7.4 & 58.1 / 22.6 & 0.09\end{array}$

Blood test

\begin{tabular}{lccc} 
Max CK, IU/L & 2080.7 & 2358.7 & 0.61 \\
$(\mathrm{SD})$ & $(2461.6)$ & $(2829.1)$ & \\
\hline
\end{tabular}


Table 1 continued

\begin{tabular}{|c|c|c|c|}
\hline $\begin{array}{l}\text { Patient } \\
\text { characteristics }\end{array}$ & $\begin{array}{l}\text { Empagliflozin } \\
\text { group, } n=46\end{array}$ & $\begin{array}{l}\text { Placebo } \\
\text { group, } \\
n=50\end{array}$ & $P$ \\
\hline HbAlc, \% (SD) & $6.82(1.00)$ & $6.89(0.92)$ & 0.7 \\
\hline $\begin{array}{l}\text { LDL-C, mg/dL } \\
(\mathrm{SD})\end{array}$ & $87.5(29.6)$ & $87.8(29.1)$ & 0.9 \\
\hline $\begin{array}{l}\mathrm{HDL}-\mathrm{C}, \mathrm{mg} / \mathrm{dL} \\
(\mathrm{SD})\end{array}$ & $45.4(12.7)$ & $46.0(10.2)$ & 0.78 \\
\hline $\begin{array}{l}\text { Triglycerides, mg/ } \\
\mathrm{dL} \text { (SD) }\end{array}$ & $161.7(119.7)$ & $\begin{array}{l}135.9 \\
(54.4)\end{array}$ & 0.18 \\
\hline $\begin{array}{l}\text { Uric acid, } \mathrm{mg} / \mathrm{dL} \\
\text { (SD) }\end{array}$ & $5.8(1.4)$ & $5.7(1.5)$ & 0.9 \\
\hline $\begin{array}{l}\text { Creatinine, } \mathrm{mg} / \mathrm{dL} \\
(\mathrm{SD})\end{array}$ & $0.92(0.2)$ & $0.92(1.2)$ & 0.39 \\
\hline $\begin{array}{l}\mathrm{eGFR}, \mathrm{mL} / \mathrm{min} / \\
1.73 \mathrm{~m}^{2}(\mathrm{SD})\end{array}$ & $64.6(15.0)$ & $66.1(15.7)$ & 0.62 \\
\hline $\begin{array}{l}\text { Hematocrit, \% } \\
(\mathrm{SD})\end{array}$ & $40.5(4.6)$ & $40.3(4.2)$ & 0.86 \\
\hline $\begin{array}{l}\text { NT-proBNP, pg/ } \\
\text { mL (SD) }\end{array}$ & $\begin{array}{l}1028.7 \\
(1105.6)\end{array}$ & $\begin{array}{l}1270.6 \\
(1521.0)\end{array}$ & 0.45 \\
\hline
\end{tabular}

$A 1 c$ glycated hemoglobin, $A C E I$ angiotensin-converting enzyme inhibitor, $A R B$ angiotensin-receptor blocker, $B M I$ body mass index, $C K$ creatine kinase, $D P P-4$ dipeptidyl peptidase-4, $E$ peak early diastolic phase mitral inflow velocity, $e^{\prime}$ mitral annular velocity, $e G F R$ estimated glomerular filtration rate, $H D L$ - $C$ high-density lipoprotein cholesterol, $L D L-C$ low-density lipoprotein cholesterol, $M R A$ mineralocorticoid receptor antagonist, $N T$-proBNP $\mathrm{N}$-terminal pro b-type natriuretic peptide, NYHA New York Heart Association, SD Standard deviation, TRPG trans-tricuspid pressure gradient

intergroup difference was observed at 12 and 24 weeks (Fig. 1a, c). On the contrary, the $\mathrm{N}$-terminal pro b-type natriuretic peptide (NTproBNP) level was decreased in both groups (1028.7-370.3 pg/mL, $\quad P<0.001, \quad$ and $1270.6-673.7 \mathrm{pg} / \mathrm{mL}, \quad P<0.01, \quad$ respectively), and intergroup differences were not significant $(P=0.91)$ (Fig. 1d; Table 2). Blood test results are presented in Table 2 During the trial period, no difference was observed between the groups in terms of glycated hemoglobin (HbA1c) levels. Compared to the placebo group, the empagliflozin group exhibited significantly higher hematocrit levels and lower uric acid levels at 24 weeks. The decrease in PVS was defined as a change of $<-4.5 \%$, which was the median value calculated using the change in PVS ( $\triangle \mathrm{PVS}$ ) of patients from baseline to 24 weeks. Univariate and multivariate logistic regression analyses adjusted for confounding variables (age, NTproBNP levels, change in body weight, systolic blood pressure, HbA1c levels) indicated that the decrease in PVS was associated with empagliflozin use (odds ratio [OR] 2.61, 95\% confidence interval (CI) 1.11-6.15, $P=0.028$, and OR 3.76, 95\% CI 1.11-12.72, $P=0.033$ for univariate and multivariate models, respectively) (Table 3 ). Additionally, $\triangle \mathrm{PVS}$ was not significantly correlated with the change in NT-proBNP $(\Delta \mathrm{NT}$ proBNP) in both the empagliflozin $(r=0.194$, $P=0.289)$ and placebo $(r=0.254, P=0.109)$ groups.

\section{DISCUSSION}

A previous study reported that a PVS $>-4 \%$ was associated with the worst prognosis [1]. Here, the NT-proBNP levels were significantly decreased in both the empagliflozin and placebo groups. Moreover, $\triangle$ PVS had no correlation with $\triangle$ NT-proBNP in both groups. In the previous study, canagliflozin, another SGLT2 inhibitor, showed no robust effects on NTproBNP levels in patients with T2DM and CHF [6]. Moreover, the DEFINE-HF trial showed that in patients with heart failure and reduced ejection fraction with and without T2DM, the use of dapagliflozin over 12 weeks did not affect the mean NT-proBNP level; however an increased proportion of patients on this drug experienced clinically meaningful improvements in the heart failure-related health status, according to the Kansas City Cardiomyopathy Questionnaire overall summary score [7]. We showed that empagliflozin reduced circulating PV independent of NT-proBNP levels. The lack of correlation between $\triangle \mathrm{PVS}$ and $\triangle \mathrm{NT}$-proBNP is similar to that observed upon valsartan administration 
Table 2 Blood tests, optimal medical therapy, and plasma volume status in the empagliflozin and placebo groups at baseline and 24 weeks

\begin{tabular}{|c|c|c|c|c|c|c|c|}
\hline \multirow{2}{*}{$\begin{array}{l}\text { Blood tests, } \\
\text { optimal } \\
\text { medical } \\
\text { therapy, and } \\
\text { PVS }\end{array}$} & \multicolumn{3}{|c|}{ Empagliflozin group $(n=46)$} & \multicolumn{3}{|c|}{ Placebo group $(n=50)$} & \multirow{2}{*}{$\begin{array}{l}\text { Intergroup } \\
P\end{array}$} \\
\hline & Baseline & 24 weeks & $P$ & Baseline & 24 weeks & $P$ & \\
\hline \multicolumn{8}{|l|}{ Blood tests } \\
\hline HbAlc (\%) & $6.8 \pm 1.0$ & $6.6 \pm 0.9$ & 0.10 & $6.9 \pm 0.9$ & $6.8 \pm 1.0$ & 0.34 & 0.50 \\
\hline $\begin{array}{l}\text { Hematocrit } \\
(\%)\end{array}$ & $40.5 \pm 4.6$ & $44.2 \pm 3.9$ & $<0.001$ & $40.3 \pm 4.2$ & $40.5 \pm 4.2$ & 0.81 & $<0.0001$ \\
\hline $\begin{array}{l}\text { Uric acid } \\
(\mathrm{mg} / \mathrm{dL})\end{array}$ & $5.8 \pm 1.4$ & $4.9 \pm 1.4$ & $<0.001$ & $5.7 \pm 1.5$ & $5.8 \pm 1.5$ & 0.82 & $<0.0001$ \\
\hline $\begin{array}{l}\text { eGFR } \\
\text { (equivalent) } \\
(\mathrm{mL} / \mathrm{min} / \\
\left.1.73 \mathrm{~m}^{2}\right)\end{array}$ & $64.6 \pm 15.0$ & $64.4 \pm 16.8$ & 0.84 & $66.1 \pm 15.7$ & $62.8 \pm 15.4$ & 0.02 & 0.10 \\
\hline $\begin{array}{l}\text { Serum } \\
\text { creatinine } \\
(\mathrm{mg} / \mathrm{dL})\end{array}$ & $0.92 \pm 0.19$ & $0.94 \pm 0.25$ & 0.44 & $0.89 \pm 0.20$ & $0.94 \pm 0.21$ & 0.01 & 0.24 \\
\hline $\begin{array}{l}\text { NT-proBNP } \\
(\mathrm{pg} / \mathrm{mL})\end{array}$ & $1028.7 \pm 1105.6$ & $370.3 \pm 530.9$ & $<0.001$ & $1270.6 \pm 1521.0$ & $673.7 \pm 1151.1$ & $<0.01$ & 0.91 \\
\hline $\begin{array}{l}\text { LDL-C (mg/ } \\
\mathrm{dL})\end{array}$ & $87.5 \pm 29.6$ & $79.4 \pm 21.3$ & 0.06 & $87.8 \pm 29.1$ & $81.0 \pm 25.0$ & 0.09 & 0.83 \\
\hline $\begin{array}{l}\text { HDL-C } \\
(\mathrm{mg} / \mathrm{dL})\end{array}$ & $45.4 \pm 12.7$ & $49.8 \pm 13.0$ & $<0.001$ & $46.0 \pm 10.2$ & $49.2 \pm 9.2$ & 0.01 & 0.52 \\
\hline $\mathrm{TG}(\mathrm{mg} / \mathrm{dL})$ & $161.7 \pm 119.7$ & $145.5 \pm 75.0$ & 0.25 & $135.9 \pm 54.3$ & $141.0 \pm 59.1$ & 0.67 & 0.30 \\
\hline AST (U/L) & $24.7 \pm 7.9$ & $23.2 \pm 8.5$ & 0.30 & $24.4 \pm 10.3$ & $25.4 \pm 14.0$ & 0.47 & 0.21 \\
\hline $\operatorname{ALT}(\mathrm{U} / \mathrm{L})$ & $26.4 \pm 14.8$ & $22.2 \pm 13.1$ & 0.04 & $26.6 \pm 16.4$ & $24.2 \pm 11.9$ & 0.20 & 0.54 \\
\hline $\begin{array}{l}\gamma \text {-GTP }(\mathrm{U} / \\
\mathrm{L})\end{array}$ & $39.6 \pm 29.1$ & $40.0 \pm 40.2$ & 0.92 & $32.4 \pm 18.9$ & $39.2 \pm 38.1$ & 0.03 & 0.16 \\
\hline \multicolumn{8}{|c|}{ Optimal medical therapy } \\
\hline $\begin{array}{l}\beta \text {-Blocker, } \\
n(\%)\end{array}$ & $41(89.1)$ & $41(89.1)$ & 1.00 & $38(76)$ & $38(76)$ & 1.00 & 0.09 \\
\hline $\begin{array}{l}\text { Diuretic, } \\
n(\%)\end{array}$ & $8(17.4)$ & $6(13.0)$ & 0.57 & $11(22)$ & $10(20)$ & 0.81 & 0.36 \\
\hline MRA, $n(\%)$ & $11(23.9)$ & $11(23.9)$ & 1.00 & $12(24)$ & $12(24)$ & 1.00 & 0.99 \\
\hline ACEI, $n(\%)$ & $23(50)$ & $20(43.5)$ & 0.54 & $28(56)$ & $22(44)$ & 0.23 & 0.96 \\
\hline $\mathrm{ARB}, n(\%)$ & $22(47.8)$ & $21(45.7)$ & 0.84 & $19(38)$ & $19(38)$ & 1.00 & 0.45 \\
\hline
\end{tabular}


Table 2 continued

\begin{tabular}{|c|c|c|c|c|c|c|c|}
\hline \multirow{2}{*}{$\begin{array}{l}\text { Blood tests, } \\
\text { optimal } \\
\text { medical } \\
\text { therapy, and } \\
\text { PVS }\end{array}$} & \multicolumn{3}{|c|}{ Empagliflozin group $(n=46)$} & \multicolumn{3}{|c|}{ Placebo group $(n=50)$} & \multirow{2}{*}{$\begin{array}{l}\text { Intergroup } \\
P\end{array}$} \\
\hline & Baseline & 24 weeks & $P$ & Baseline & 24 weeks & $P$ & \\
\hline
\end{tabular}

PVS

PVS (\%) $\quad-4.72 \pm 8.95 \quad-9.79 \pm 8.07<0.001 \quad-3.77 \pm 9.64 \quad-4.04 \pm 10.12 \quad 0.79 \quad<0.001$

ALT Alanine aminotransferase, $A S T$ aspartate aminotransferase, $P V S$ plasma volume status, $T G$ triglycerides, $\gamma$-GTP $\gamma$ glutamyl transpeptidase
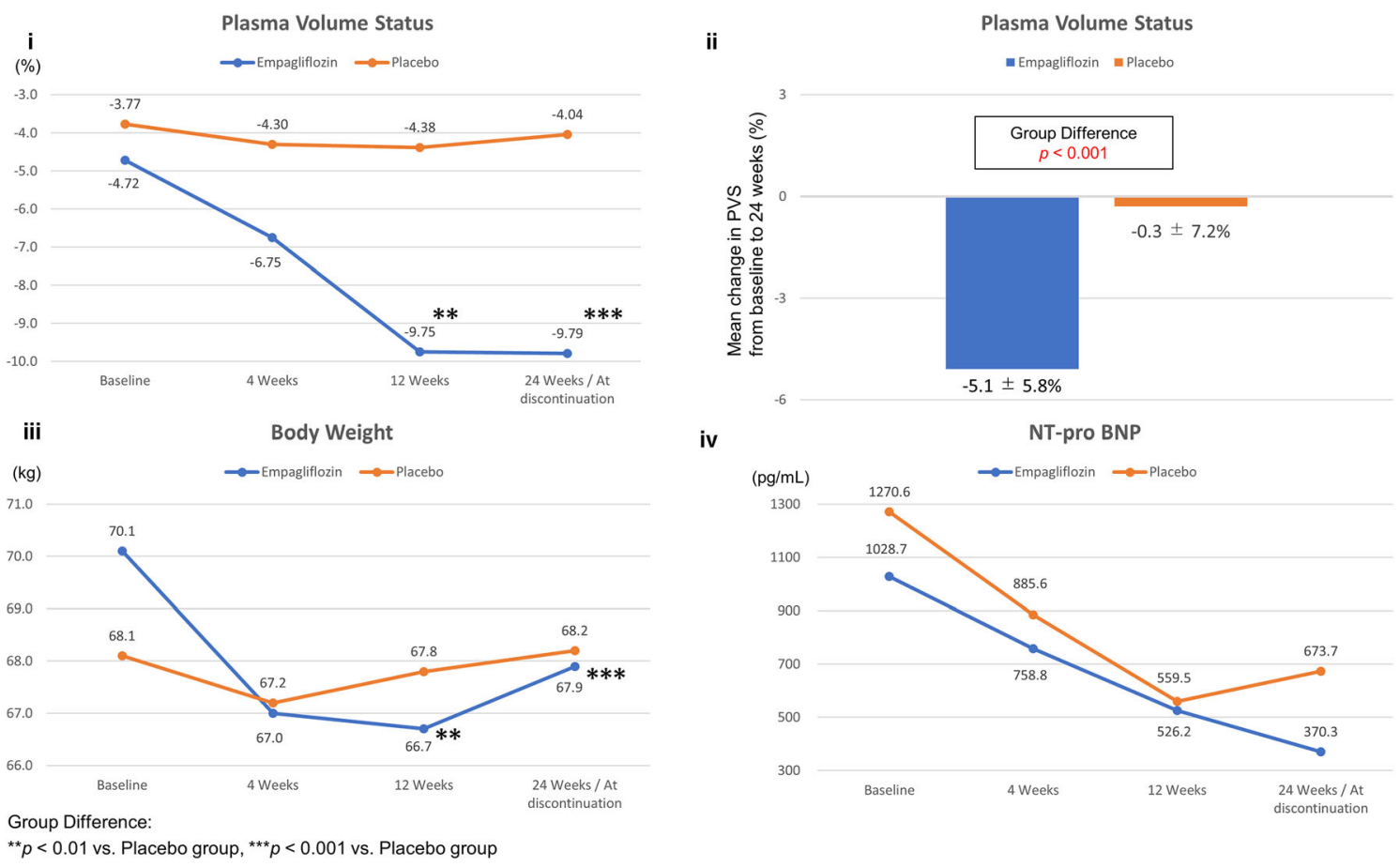

iv

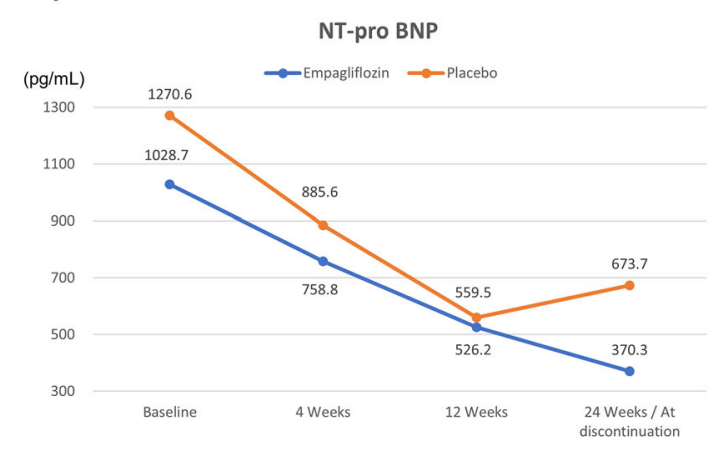

Fig. 1 i Time-course of change in plasma volume status (PVS) from baseline to 24 weeks. ii Change in PVS between baseline and 24 weeks. iii Time-course of change in body weight from baseline to 24 weeks. iv Time-course of change in $\mathrm{N}$-terminal pro b-type natriuretic peptide $(N T$-proBNP) levels from baseline to 24 weeks

in the Heart Failure Trial [1]. The reason for such a result is unclear, and further research is warranted. The novelty of the current study is that early administration of empagliflozin in patients with AMI and T2DM reduced PVS over a 24 -week period. As this study corresponds to a subanalysis, a large-scale, randomized, controlled trial with PVS as the primary endpoint is required in the future to confirm our results.

This study has several limitations. First, the trial period was only 24 weeks; nevertheless, no study has previously examined how PVS changes during 24 weeks after the administration of 
Table 3 Odds ratio associated with $\triangle$ PVS $<-4.5 \%$

\begin{tabular}{|c|c|c|c|c|}
\hline \multirow[t]{2}{*}{ Variables } & \multicolumn{2}{|l|}{ Univariate } & \multicolumn{2}{|l|}{ Multivariate } \\
\hline & OR (95\% CI) & $P$ & OR (95\% CI) & $P$ \\
\hline Empagliflozin & $2.61(1.11-6.15)$ & 0.028 & $3.76(1.11-12.72)$ & 0.033 \\
\hline Age & $1.00(0.96-1.04)$ & 0.931 & & \\
\hline NT-proBNP & $1.00(1.00-1.01)$ & 0.355 & & \\
\hline$\Delta$ Body weight & $0.97(0.86-1.09)$ & 0.588 & & \\
\hline$\Delta$ Systolic blood pressure & $1.01(0.98-1.03)$ & 0.697 & & \\
\hline$\Delta \mathrm{HbA1c}$ levels & $0.99(0.58-1.70)$ & 0.977 & & \\
\hline
\end{tabular}

$C I$ Confidence interval, $O R$ odds ratio, $\Delta$ delta

SGLT2 inhibitors. Second, our sample size was small. Third, we excluded patients treated with insulin, glucagon-like peptide 1 analogs, and high doses of sulfonylureas, as well as patients with $\mathrm{HbA} 1 \mathrm{c} \geq 10 \%$. Therefore, this study did not include patients with poor glycemic control. Finally, although $20 \%$ of patients were women, the results were comparable even when the data of female patients were excluded from the analysis.

\section{CONCLUSION}

In conclusion, we showed that empagliflozin reduced circulating PV in patients with AMI and T2DM.

\section{ACKNOWLEDGEMENTS}

We wish to thank the staff and patients who participated in the EMBODY trial.

Funding. This work and the journal's Rapid Service were supported by Boehringer Ingelheim and Eli Lilly and Company [grant number: 1245-0175]. The funding agencies had no role in designing or conducting the trial.

Editorial Assistance. We wish to thank all Editage staffs who proofread our paper in Cactus Communications (supported by Boehringer
Ingelheim and Eli Lilly and Company [grant number: 1245-0175]).

Authorship. All named authors meet the International Committee of Medical Journal Editors (ICMJE) criteria for authorship for this article, take responsibility for the integrity of the work as a whole, and have given their approval for this version to be published.

Authors' Contributions. YH, KM, ST, and YT analyzed the data. YH, YK, KY, YI, TY, and TH wrote the manuscript and analyzed the data. YT, KA, and MM reviewed/edited the manuscript. YM, EK, MM, JT, and WS analyzed the data and contributed to the discussion. All authors read and approved the final manuscript.

Prior Presentation. American Heart Association Scientific Session 2020, 14 November 2020; https://www.ahajournals.org/toc/circ/ 142/Suppl_3.

Disclosures. Yu Hoshika, Yoshiaki Kubota, Kosuke Mozawa, Shuhei Tara, Yukichi Tokita, Kenji Yodogawa, Yu-ki Iwasaki, Takeshi Yamamoto, Hitoshi Takano, Yayoi Tsukada, Kuniya Asai, Masaaki Miyamoto, Yasushi Miyauchi, Eitaro Kodani, Mitsunori Maruyama, and Jun Tanabe declare no conflicts of interest. Wataru Shimizu has received honoraria and research grants from Boehringer Ingelheim. 
Compliance with Ethics Guidelines. The EMBODY trial was registered at the UMIN in November 2017 (ID: 000030158). Ethics approval was obtained from the local institutional review board of each participating center. The trial was conducted in full compliance with the articles of the Declaration of Helsinki and according to the Ethical Guidelines for Medical and Health Research Involving Human Subjects established by the Ministry of Health, Labour, and Welfare and the Ministry of Education, Culture, Sports, Science, and Technology in Japan. After initial screening for eligibility using prior medical records, each patient received an adequate explanation of the trial plan before they provided written informed consent. All participants provided written informed consent prior to study enrolment.

Data Availability. The datasets generated during and/or analyzed during the current study are available from the corresponding author on reasonable request.

Open Access. This article is licensed under a Creative Commons Attribution-NonCommercial 4.0 International License, which permits any non-commercial use, sharing, adaptation, distribution and reproduction in any medium or format, as long as you give appropriate credit to the original author(s) and the source, provide a link to the Creative Commons licence, and indicate if changes were made. The images or other third party material in this article are included in the article's Creative Commons licence, unless indicated otherwise in a credit line to the material. If material is not included in the article's Creative Commons licence and your intended use is not permitted by statutory regulation or exceeds the permitted use, you will need to obtain permission directly from the copyright holder. To view a copy of this licence, visit http://creativecommons.org/licenses/by$\mathrm{nc} / 4.0 /$.

\section{REFERENCES}

1. Ling HZ, Flint J, Damgaard M, et al. Calculated plasma volume status and prognosis in chronic heart failure. Eur J Heart Fail. 2015;17:35-43.

2. Grodin JL, Philips S, Mullens W, et al. Prognostic implications of plasma volume status estimates in heart failure with preserved ejection fraction: Insights from TOPCAT. Eur J Heart Fail. 2019;21:634-42.

3. Hakim RM. Plasmapheresis. In: Daugirdas JT, Blake PG, Ing TS, editors. Handbook of dialysis. Philadelphia: Lippincott Williams and Wilkins; 2001. p. 236.

4. Kubota Y, Yamamoto T, Tara S, et al. Effect of empagliflozin versus placebo on cardiac sympathetic activity in acute myocardial infarction patients with type 2 diabetes mellitus: Rationale. Diabetes Ther. 2018;9:2107-16.

5. Shimizu W, Kubota Y, Hoshika Y, et al. Effects of empagliflozin versus placebo on cardiac sympathetic activity in acute myocardial infarction patients with type 2 diabetes mellitus: the EMBODY trial. Cardiovasc Diabetol. 2020;19:1-12.

6. Tanaka A, Hisauchi I, Taguchi I, et al. Effects of canagliflozin in patients with type 2 diabetes and chronic heart failure: a randomized trial (CANDLE). ESC Heart Fail. 2020;7:1585-94.

7. Nassif ME, Windsor SL, Tang F, et al. Dapagliflozin effects on biomarkers, symptoms, and functional status in patients with heart failure with reduced ejection fraction: the DEFINE-HF Trial. Circulation. 2019;140:1463-76. 